Wind Energ. Sci. Discuss., doi:10.5194/wes-2016-30, 2016

Manuscript under review for journal Wind Energ. Sci.

Published: 7 September 2016

(c) Author(s) 2016. CC-BY 3.0 License.

(c) (i)

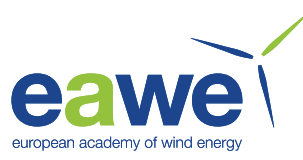

\title{
Detection of ice mass based on the natural frequencies of wind turbine blade
}

\author{
Sudhakar Gantasala, Jean-Claude Luneno, Jan-Olov Aidanpää
}

Department of Engineering Sciences and Mathematics, Luleå University of Technology, Luleå-97187, Sweden

5 Correspondence to: Sudhakar Gantasala (sudhakar.gantasala@1tu.se)

\begin{abstract}
Wind turbines installed in the cold climate regions accumulate ice on the blades affecting their aeroelastic behavior and turbine power output. It is essential to detect icing in the early stages to start the deicing systems so that the losses due to icing can be minimized. The increase in mass distribution of the blade due to icing reduces its natural frequencies and how much these frequencies reduce depends on the amount of ice mass and their location on the blade. Ice detection systems like BLADEControl (Bosch Rexroth) and fos4blade IceDetection (fos4X) systems detect ice based on the deviations in blade natural frequencies, but cannot identify the location and amount of ice mass. In this work, the authors propose a method to detect average ice mass accumulated along three zones defined along the blade based on its natural frequencies using Artificial Neural Networks (ANN). Different ice masses are added on a wind turbine blade and their natural frequencies are simulated using a finite element model of the blade vibrations. ANN is trained with the natural

15 frequencies of the iced blade as inputs and corresponding ice mass distributions used in the three zones as outputs. ANN approximates the non-linear function between inputs and outputs in the training process. After training with a large data set of possible ice mass distributions, ANN model can be used to predict ice mass distributions in the three zones for any set of natural frequencies (input to ANN) of the iced blade. NREL $5 \mathrm{MW}$ wind turbine blade is considered in this study to demonstrate the proposed method. Various cases of ice mass distributions are tested by the trained ANN model and the predicted ice mass distributions are compared against actual ice mass distribution values. ANN model is able to predict ice mass distributions exactly if they are similar to the ice mass distributions used in the training data, otherwise the ice masses are predicted with an error. Overall, the proposed method is able to approximately detect average ice mass accumulated along the blade which is not possible before.
\end{abstract}

\section{INTRODUCTION}

25 Wind turbines are increasingly installed in the northeastern and the mid-Atlantic US, Canada, and Northern Europe due to good wind resources and land availability. In these regions, humidity along with low temperatures in the winter increases the risk of ice accumulation on wind turbine components. The global wind energy installations in cold climate regions reached a capacity of $69 \mathrm{GW}$ at the end of 2012 and an additional capacity of 45-50 GW installations are forecasted between 2013 and 2017 (Navigant Research, 2012). Icing of the rotor blades results in reduced turbine power output as icing reduces the lift 
Wind Energ. Sci. Discuss., doi:10.5194/wes-2016-30, 2016

Manuscript under review for journal Wind Energ. Sci.

Published: 7 September 2016

(c) Author(s) 2016. CC-BY 3.0 License.

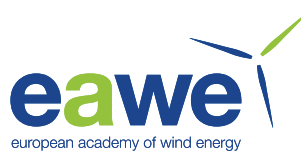

force and increases drag force (Turkia et al., 2013; Rindeskär, 2010). Nacelle vibration amplitudes increase during icing conditions, so icing can be detected more reliably using power curve analysis along with measuring nacelle vibrations (Skrimpas et al., 2015). Etemaddar et al. (2014) investigated the effects of atmospheric ice accumulation on the aerodynamic performance and structural response of the wind turbines and they predicted a bigger change in relative mean value of the dynamic response quantities for iced blades. Rissanen et al. (2016) proposed simulation parameters for predicting dynamic behavior of wind turbines with icing to generate icing design load cases for the new IEC 61400-1 ed4. Ice accumulation on the blades is not uniform and its distribution changes under different stages of icing, ice shedding during operation. Ice mass on the blade reduces its natural frequencies and raises the risks of resonance. This shift in natural frequencies can be used to detect ice and monitor its growth on the wind turbine blades both in operating and standstill conditions (King, 2008; Brenner, 2015; Brenner, 2016). Lorenzo et al. (2013) investigated the influence of ice mass on the natural frequencies of NREL 5 MW turbine by extracting model parameters through operational modal analysis. Alsabagh et al. (2015) considered different ice mass distributions as defined in ISO 12494:2001 (2001) standard on a multi megawatt wind turbine blade. They analyzed the influences of ice mass on natural frequencies and dynamic magnification factors, by considering only the mass changes in the blade.

Gantasala et al. (2015) investigated the influence of 3 different mass distributions (constant, linearly decreasing and linearly increasing mass densities) along a rotating beam on its first in-plane bending mode natural frequency. The natural frequency of the beam at different rotational speeds varies as shown in Figure 1 (Gantasala et al., 2015). They considered constant beam stiffness to show the lone influence of mass density changes on the natural frequency. The rate of change in the natural frequency with rotational frequency is influenced by the nature of mass density variation along the beam. Ice accumulation on the blade reduces its natural frequencies and how much they reduce depends on the location and amount of ice mass along the blade axis.
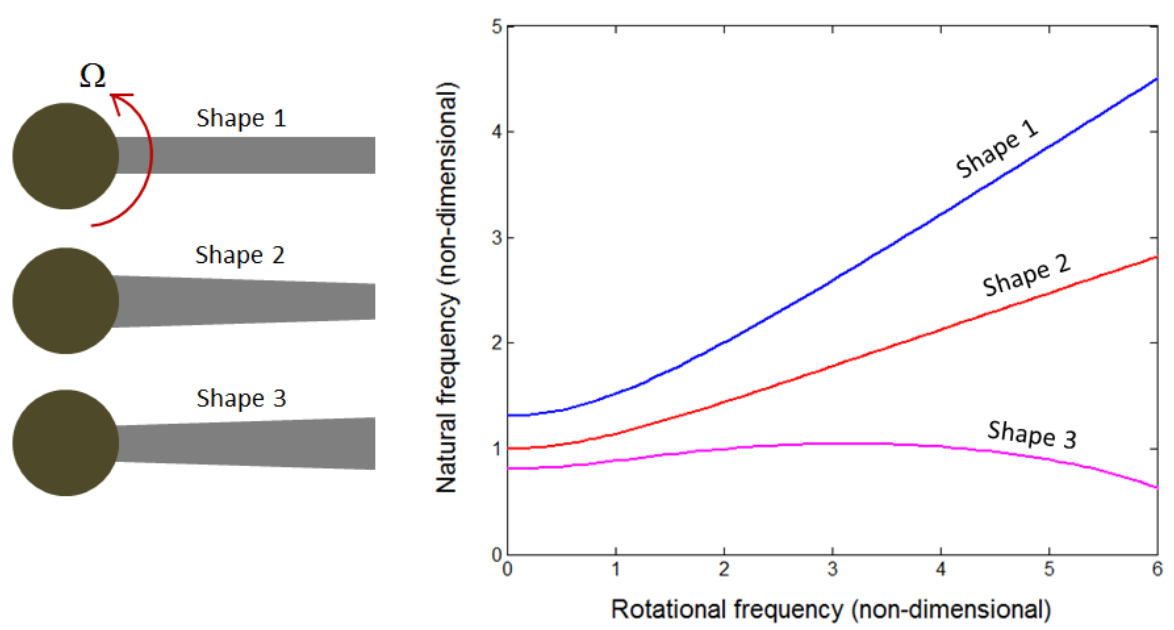

Figure 1. First in-plane bending mode natural frequency variation with increasing rotational frequency of a rotating beam (X and $\mathrm{Y}$ axis values are non-dimensionalized using the natural frequency of the uniform cross-section beam at zero speed) (Gantasala et al., 2015) 
Wind Energ. Sci. Discuss., doi:10.5194/wes-2016-30, 2016

Manuscript under review for journal Wind Energ. Sci.

Published: 7 September 2016

(c) Author(s) 2016. CC-BY 3.0 License.

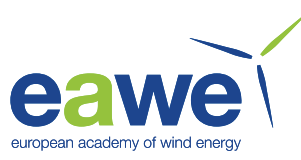

Different ice detection systems consisting nacelle and blade based systems are evaluated in Cattin et al. (2016). Out of the blade based systems, Bosch Rexroth BLADEControl system (Brenner, 2015; Brenner, 2016) and fos4blade IceDetection (fos4X data sheet, n.d.; Cattin et al., 2016) systems detect ice based on the deviations in blade natural frequencies. The spectral vibration response of a wind turbine blade during the ice growth is shown in Figure 2 (Brenner, 2015; Brenner,

5 2016) where blade natural frequencies are reduced with the ice growth. The current ice detection systems cannot identify the amount of ice mass and their location along the blade.

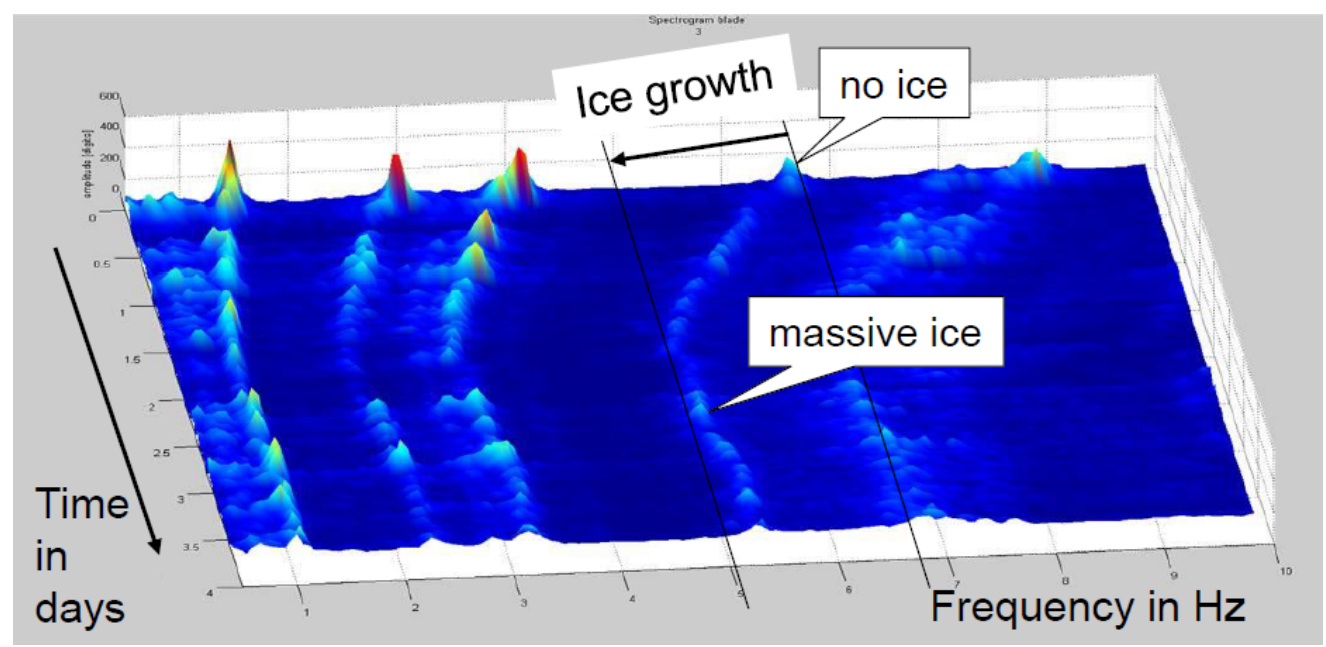

Figure 2. The spectrum of blade vibration response during the ice growth (Brenner, 2015; Brenner, 2016)

The most widely used anti-icing and de-icing systems works on the basis of heating resistance or hot air techniques

10 (Ilinca, 2011). Both these systems require external power and consume 1-4\% of annual energy production, depending on the icing severity (Peltola et al., 2003 in Ilinca, 2011). The required power to remove ice can be minimized if the location of ice mass is determined approximately so that the relevant energy needed at the appropriate locations of the blade can be supplied to remove ice. This has motivated authors to pursue the idea to determine the location of ice mass and the amount of ice mass accumulated on the blade. The authors propose a method based on the Artificial Neural Networks (ANN) model to

15 detect ice mass accumulated on the blade by dividing its length into three zones as shown in Figure 3 . The inner half of the blade is considered as Zone-1 and the outer half of the blade is divided into two zones, Zone- $2 \& 3$ which accumulate more ice than the Zone-1. This is due to the fact that the aerofoil sections in this part of the blade sweep more area in the rotation and also experience wind at higher relative velocity. The natural frequencies of the blade change differently with the amount of ice mass and their location. Different ice masses are considered in the three zones defined along the blade and their natural

20 frequencies are simulated using a finite element model of the blade vibrations. The ANN model is trained with blade natural frequencies as inputs and the corresponding ice masses in the three zones used in the simulations as outputs. ANN's are widely used in many areas for function approximations, pattern recognitions. Their applications in wind energy are mainly focused on wind power forecasting and wind speed prediction, wind turbine power control, identification and evaluation of 
Wind Energ. Sci. Discuss., doi:10.5194/wes-2016-30, 2016

Manuscript under review for journal Wind Energ. Sci.

Published: 7 September 2016

(c) Author(s) 2016. CC-BY 3.0 License.

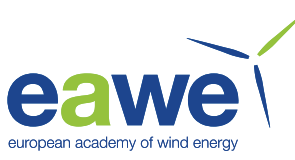

faults (Ata, 2015). The first application of ANN to identify average ice mass accumulated on the blade is proposed in this work. The advantage of using ANN for ice mass detection is that it only requires a data set of iced blade natural frequencies (input to ANN model) and ice mass distributions (output of the ANN model) associated with them. ANN approximates nonlinear function between inputs and outputs which can be used to predict ice mass distributions for any given set of iced blade natural frequencies. NREL $5 \mathrm{MW}$ wind turbine blade structural data is considered in this study and a data set of blade natural frequencies for different ice mass distributions is created to train the ANN model. Finally, few ice mass distribution cases are considered along the blade whose natural frequencies are given as input to the trained network model and the predicted ice masses are compared with the actual values of ice masses used.

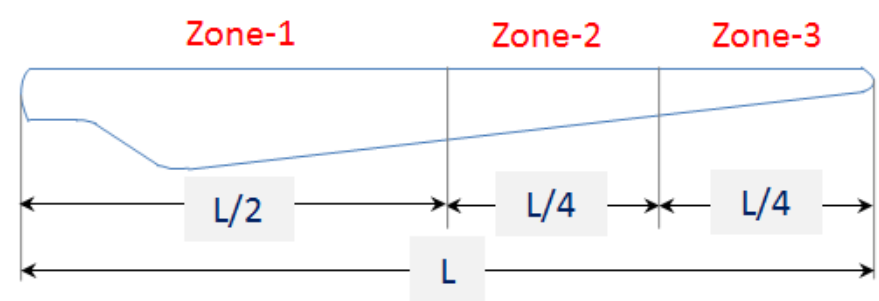

10 Figure 3. Division of blade length into different zones for ice mass prediction

This paper is organized as follows: the first section gives introduction and discusses objectives of the paper, second section explains the derivation of governing equations of motion of the blade vibrations, third section explains different ice mass distribution guidelines, fourth section gives introduction to the ANN model and fifth section consists of results and discussions of the paper.

\section{II. STRUCTURAL MODEL}

Wind turbine blades are made of aerofoil cross sections which are twisted and tapered along the blade axis. The vibration behavior in bending and torsion are therefore coupled. Kim and Lee (2008) analyzed wind turbine blade modal characteristics using the assumed mode method. Partial differential equations governing blade in-plane (edgewise), out-ofplane (flapwise), axial and torsional vibrations are derived in this section using Hamilton's principle based on the derivation in Kim and Lee (2008). These equations are then analyzed using finite element method (FEM). A rotating coordinate system OXYZ fixed at the hub center as shown in Figure 4 is considered to derive governing equations of the blade vibrations. Pitch axis of the blade (the line joining quarter chord points of the aerofoil sections) coincides with the $\mathrm{X}$ axis of the coordinate system. Blade vibrations degrees of freedom (DOF) in axial $(u)$, edgewise $(v)$, flapwise $(w)$ and torsional $(\varphi)$ motions are considered in this study. 
Wind Energ. Sci. Discuss., doi:10.5194/wes-2016-30, 2016

Manuscript under review for journal Wind Energ. Sci.

Published: 7 September 2016

(c) Author(s) 2016. CC-BY 3.0 License.

(c) (1)
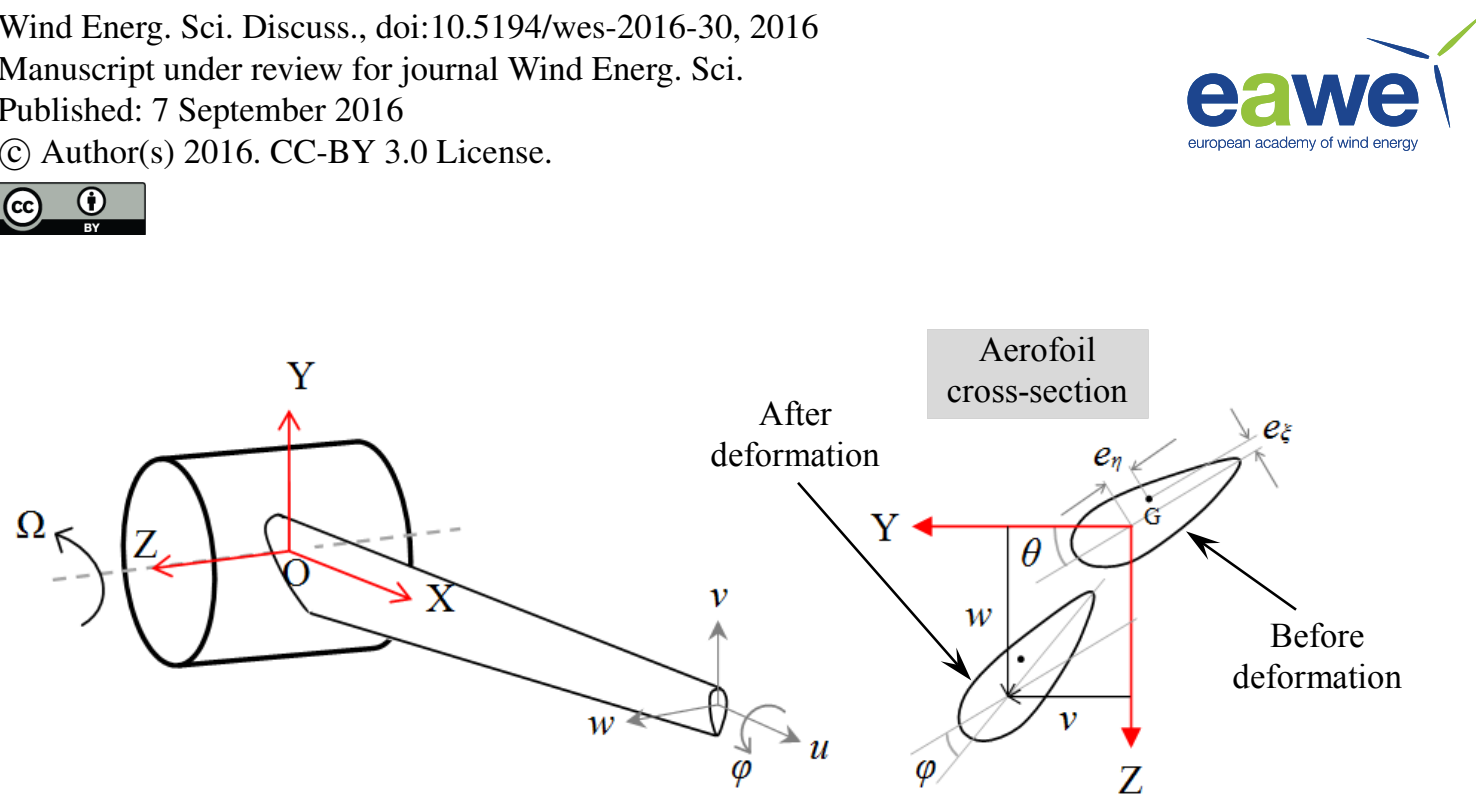

Figure 4. Schematic diagram of the wind turbine blade with vibrations DOF

The position vector of the center of gravity $(\mathrm{G})$ of aerofoil section at a distance $x$ from the blade root is given in Equation (1), its velocity and angular velocity vectors are given in Equations (2) and (3) which are used to calculate the

$\vec{r}_{G}=\left\{\begin{array}{c}x+h+u \\ v+\left(e_{\eta} \cos \theta-e_{\xi} \sin \theta\right)-\left(e_{\eta} \sin \theta+e_{\xi} \cos \theta\right) \varphi \\ w+\left(e_{\eta} \sin \theta+e_{\xi} \cos \theta\right)+\left(e_{\eta} \cos \theta-e_{\xi} \sin \theta\right) \varphi\end{array}\right\}$

$\vec{V}_{G}=\dot{\vec{r}}_{G}+\left\{\begin{array}{l}0 \\ 0 \\ \Omega\end{array}\right\} \times \vec{r}_{G}$

10

$\vec{\omega}=\left\{\begin{array}{l}\dot{\varphi} \\ 0 \\ 0\end{array}\right\}+\left[\begin{array}{ccc}1 & 0 & 0 \\ 0 & 1 & \varphi \\ 0 & -\varphi & 1\end{array}\right]\left\{\begin{array}{l}0 \\ 0 \\ \Omega\end{array}\right\}$

where, $h$ is the hub radius; $e_{\eta}, e_{\xi}$ are the distances from the pitch axis to the center of gravity along the chord line and perpendicular to the chord line; $\theta$ is the sum of blade twist and pitch angles; $\Omega$ is the blade angular velocity; $(\cdot)$ refers to the

15 temporal differentiation.

The equations of kinetic energy, strain energy and potential energy (due to the centrifugal and gravitational forces) of the whole blade are given in Equations (4)-(6).

$T=\frac{1}{2} \int_{0}^{l}\left(\rho A\left|\vec{V}_{G}\right|^{2}+J_{P}|\vec{\omega}|^{2}\right) d x$

$20 \quad \Pi_{E}=\frac{1}{2} \int_{0}^{l}\left(E A\left(u^{\prime}\right)^{2}+E I_{Y}\left(w^{\prime \prime}\right)^{2}+E I_{Z}\left(v^{\prime \prime}\right)^{2}+2 E I_{Y Z}\left(w^{\prime \prime}\right)\left(v^{\prime \prime}\right)+G J\left(\varphi^{\prime}\right)^{2}\right) d x$ 
Wind Energ. Sci. Discuss., doi:10.5194/wes-2016-30, 2016

Manuscript under review for journal Wind Energ. Sci.

Published: 7 September 2016

(c) Author(s) 2016. CC-BY 3.0 License.

$\Pi_{C+G}=\frac{1}{2} \int_{0}^{l} F_{a x}\left(\left(w^{\prime}\right)^{2}+\left(v^{\prime}\right)^{2}\right) d x+\int_{0}^{l} \rho A g \sin (\Omega t)\left(v-\left(e_{\eta} \sin \theta+e_{\xi} \cos \theta\right) \varphi\right) d x$

where, $F_{a x}=\rho A \Omega^{2}\left\{h(l-x)+\frac{1}{2}\left(l^{2}-x^{2}\right)\right\}+\rho A g(l-x) \cos (\Omega t)$ is the axial force acting on the blade section which is at a distance of $x$ from the blade root; $T, \Pi_{E}, \Pi_{C+G}$ are the blade's kinetic energy, strain energy and potential energy; $\rho A, J_{P}$ are the linear mass density and polar mass moment of inertia of the blade section; $l$ is the blade length; $E I_{Y}, E I_{Z}, E I_{Y Z}$ are the blade flexural rigidities and $G J$ is the torsional rigidity of the blade; $g$ is the acceleration due to gravity; (') refers to the spatial differentiation with respect to $x$.

Work done by the generalized forces $f_{u}, f_{v}, f_{w}, f_{\varphi}$ corresponding to the $u, v, w, \varphi$ DOF is given below.

$W_{E}=f_{u} u+f_{v} v+f_{w} w+f_{\varphi} \varphi$

Linear partial differential equations governing the vibration behavior of wind turbine blade are derived using the Hamilton's principle given in Equation (8) by assuming small amplitude vibrations and resulting equations are given in Appendix.

$\delta \int_{t_{1}}^{t_{2}}\left[T-\left(\Pi_{E}+\Pi_{C+G}\right)+W_{E}\right] d t=0$

NREL 5 MW wind turbine (Jonkman et al., 2009) blade structural details are considered in this study. Partial

15 differential equations (given in Appendix) obtained from the Equation (8) are discretized and analyzed using finite element method (FEM). Eigenvalue analysis is carried out to find natural frequencies of the blade vibration modes. First few natural frequencies of the stationary blade and the blade rotating at its rated speed $12.1 \mathrm{rpm}$ are given in Table 1 . These values are compared with those predicted using the BModes tool (Gunjit, 2008). Natural frequencies calculated using the current FEM model closely matches with those predicted using the BModes tool and the error between these frequencies are shown in

20 Figure 5 . Most of the frequencies are predicted within $\pm 1 \%$ error except the torsional frequency. This large difference in the torsional frequency may be due to different modeling approaches used in the derivation of equations of motion; however torsional frequency is not used in the proposed ice detection method.

\section{ICE ACCRETION ON THE BLADE}

Two types of icing occur in wind turbines: glaze and rime ice. Glaze ice is caused by freezing rain or wet in-cloud icing, and

normally causes smooth evenly distributed ice accretion. Rime forms through the deposition of super-cooled fog or cloud droplets and is the most common form of in-cloud icing. Rime tends to form vanes on the windward side of the blades. Ice formation on the blades depends on parameters like wind velocity, ambient temperature, liquid water content (LWC), median volume diameter (MVD) or droplet size and duration of the icing event. All these parameters vary stochastically in space, time and these parameters are different for different wind turbine sites and they even change for turbines within the 
Wind Energ. Sci. Discuss., doi:10.5194/wes-2016-30, 2016

Manuscript under review for journal Wind Energ. Sci.

Published: 7 September 2016

(c) Author(s) 2016. CC-BY 3.0 License.

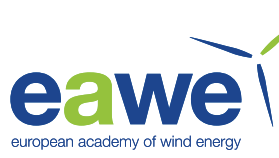

(c) (i)

Table 1: Natural frequencies of the NREL 5 MW wind turbine blade

\begin{tabular}{ccccc}
\hline $\begin{array}{c}\text { Vibration } \\
\text { mode }\end{array}$ & $\begin{array}{c}c \\
\text { BModes } \\
\text { (Gunjit, 2008) }\end{array}$ & Current study & $\begin{array}{c}\text { Natural frequencies (Hz) } \\
\text { At 12.1 rpm } \\
\text { (Gunjit, 2008) }\end{array}$ & Current study \\
\hline $1^{\text {st }}$ Flapwise & 0.6755 & 0.6770 & 0.7275 & 0.7196 \\
$1^{\text {st }}$ Edgewise & 1.0850 & 1.0843 & 1.0938 & 1.1303 \\
$2^{\text {nd }}$ Flapwise & 1.9451 & 1.9541 & 2.0043 & 2.0168 \\
$2^{\text {nd }}$ Edgewise & 3.9955 & 3.9898 & 4.0183 & 4.0302 \\
$3^{\text {rd }}$ Flapwise & 4.4994 & 4.5529 & 4.5509 & 4.6110 \\
$1^{\text {st }}$ Torsion & 5.8281 & 5.5548 & 5.8332 & 5.5520 \\
$4^{\text {th }}$ Flapwise & 7.9744 & 8.0679 & 8.0278 & 8.1313 \\
$3^{\text {rd }}$ Edgewise & 9.3693 & 9.2590 & 9.3921 & 9.2947 \\
\hline
\end{tabular}

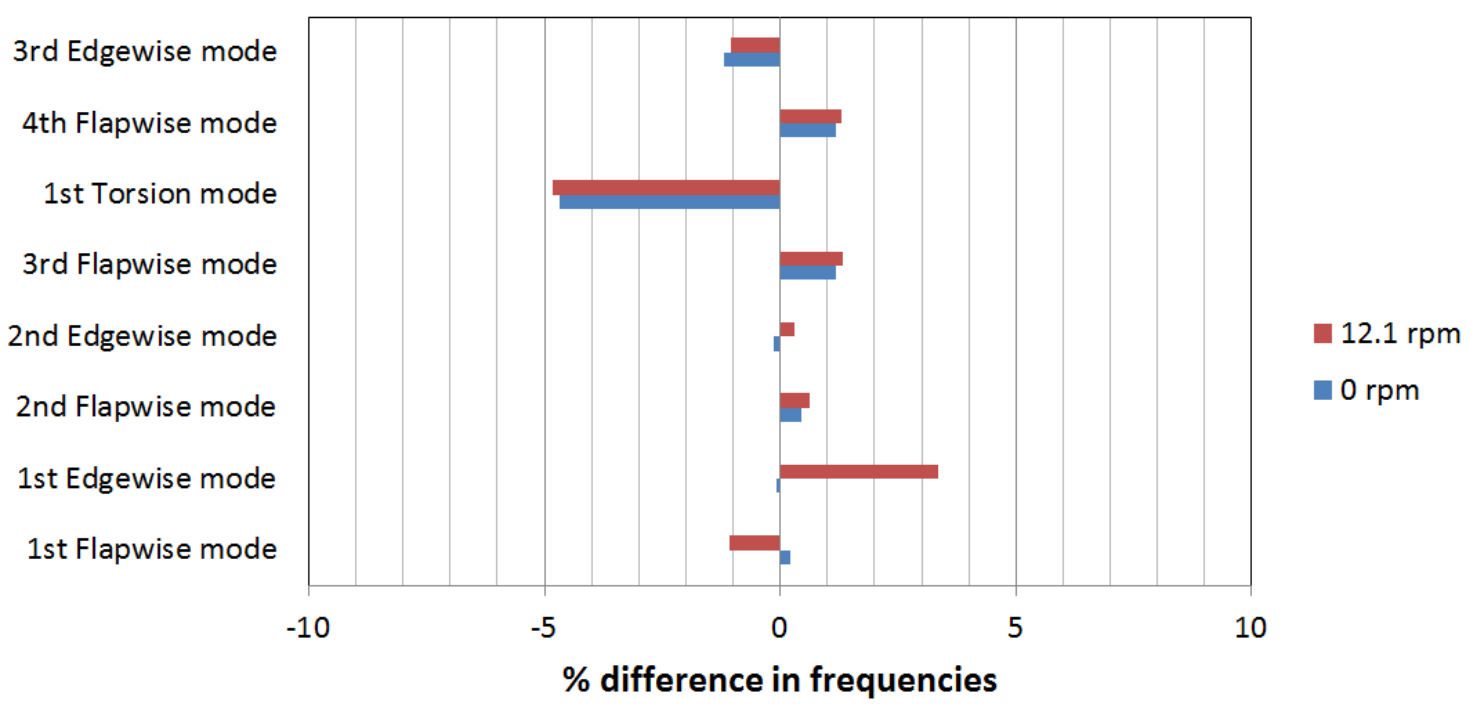

Figure 5. Error between natural frequencies predicted using current FEM model and BModes tool

site. Ice accumulation on the wind turbine blades is not same across the blade length. Blade accumulates more ice away from

5 the blade root as it sweeps through a larger area in rotation and collects more ice. Three different guidelines for the ice mass calculation are available in the literature: ISO 12494:2001 (2001), GL (Germanischer Lloyd, 2010) and VTT (Rissanen et al., 2016) formulas. Rissanen et al. (2016) calculated ice mass distributions based on these three formulas on a wind turbine 
Wind Energ. Sci. Discuss., doi:10.5194/wes-2016-30, 2016

Manuscript under review for journal Wind Energ. Sci.

Published: 7 September 2016

(c) Author(s) 2016. CC-BY 3.0 License.

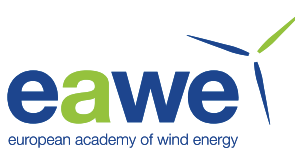

blade which is shown in Figure 6. These guidelines specify maximum ice mass that can be accumulated based on the dimensions of turbine rotor and the duration of icing event. The ice mass estimation in ISO 12494:2001 depend on the duration of icing event, the width of the blade section and wind speed. The ice mass predicted using this guideline increases with the duration of icing event and also predicts more ice near the root due to the higher width of blade section. Ice on the blades causes more loads and vibrations in the turbine. In order to certify wind turbines and its components for the cold climate operation, GL (Germanischer Lloyd, 2010) proposed a guideline that defines the maximum ice mass distribution on the blade to calculate loads acting on the turbine in various design load cases. The actual ice mass may be lower than this limit, but the turbines are certified for loads corresponding to this mass limit. In the GL guideline, ice mass density linearly increases from zero at the blade root to a value $\mu_{E}$ till the blade's half-length and thereafter a constant ice mass density towards the tip. The value of $\mu_{E}$ is calculated as follows (Germanischer Lloyd, 2010):

$\mu_{E}=\rho_{E} k c_{\min }\left(c_{\max }+c_{\min }\right)$

where, $\rho_{E}$ is the ice density $\left(700 \mathrm{~kg} / \mathrm{m}^{3}\right) ; k=0.00675+0.3 e^{\left(-0.32 \frac{R}{R_{1}}\right)}, R$ is the rotor radius in meter unit, $R_{l}=1 \mathrm{~m} ; c_{\max }$, $c_{\min }$ are the maximum and minimum chord lengths of the blade in meter unit. A new linearly increasing ice mass distribution guideline is developed by VTT (Rissanen et al., 2016) in terms of the blade chord length at $85 \%$ of radius, rotor radius and a variable determined from turbine load measurements.

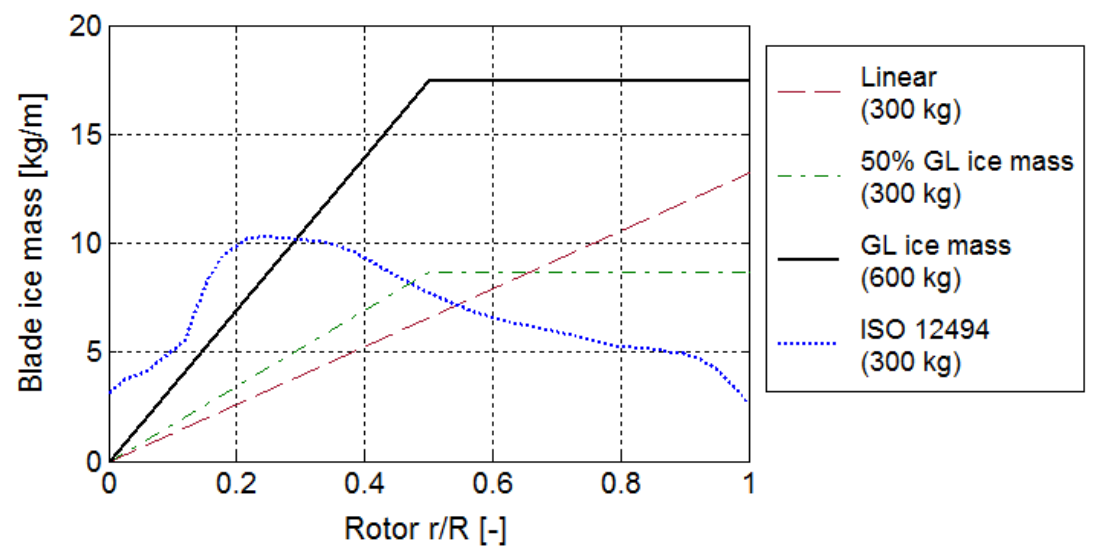

Figure 6. Different ice mass distributions defined in the literature (Rissanen et al., 2016)

Mass distribution of the NREL 5 MW wind turbine blade considered in this study is shown in Figure 7(a) along with the iced blade mass distribution estimated using GL formula. The $\mu_{E}$ value for this turbine blade is $40.73 \mathrm{~kg} / \mathrm{m}$ and the maximum ice mass on the blade according to GL formula is calculated to be $1878 \mathrm{~kg}$ (10.66\% of blade mass). The distribution of the GL ice mass in the three zones divided along the blade length is shown in Figure 7(b). 
Wind Energ. Sci. Discuss., doi:10.5194/wes-2016-30, 2016

Manuscript under review for journal Wind Energ. Sci.

Published: 7 September 2016

(c) Author(s) 2016. CC-BY 3.0 License.

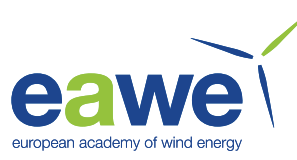

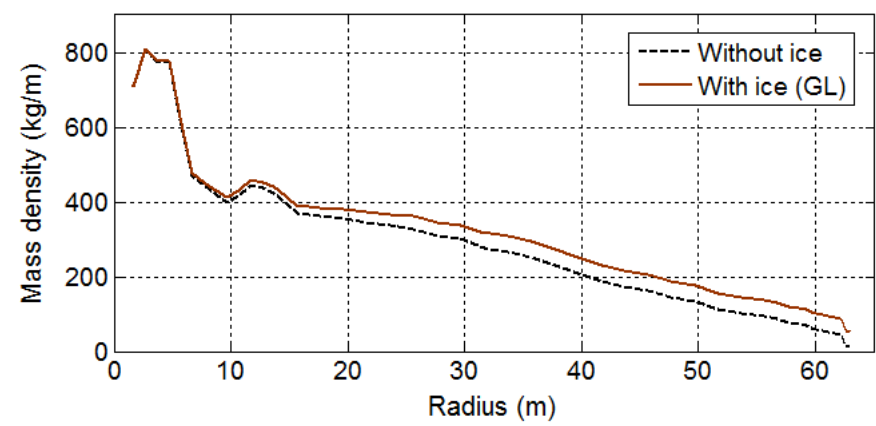

(a)

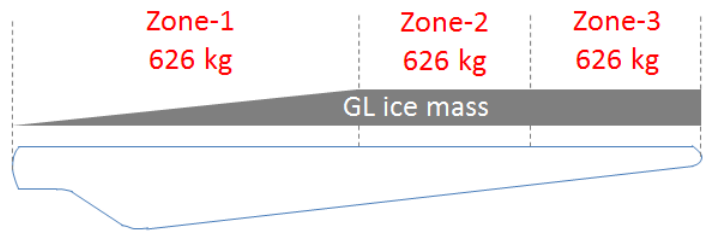

(b)

Figure 7. (a) NREL 5 MW blade mass distribution with ice, (b) GL ice mass distribution

To find the influence of ice mass location on blade natural frequencies, an ice mass of $100 \mathrm{~kg}$ (which is about $0.58 \%$ of blade mass) in considered in one zone at a time on this wind turbine blade and it is distributed with constant linear mass density. The ice mass value used above is well below the GL limit shown in Figure 7(b). The natural frequencies of iced blade rotating at $12.1 \mathrm{rpm}$ are given in the Table 2. The reduction in natural frequencies is sensitive to the ice mass location and the frequencies reduce more when the ice mass is located away from the blade root. In this work, this behavior is used to predict the average amount of ice mass accumulated in the three zones defined on the blade based on its blade natural frequencies using Artificial Neural Networks explained in the next section.

Table 2: Changes in the blade natural frequencies with the location of ice mass: $100 \mathrm{~kg}$ ice mass is considered in three zones with ice present in one zone at a time

\begin{tabular}{|c|c|c|c|c|c|c|}
\hline \multirow{2}{*}{$\begin{array}{l}\text { Vibration } \\
\text { mode }\end{array}$} & \multicolumn{2}{|c|}{ Ice mass in Zone 1} & \multicolumn{2}{|c|}{ Ice mass in Zone 2} & \multicolumn{2}{|c|}{ Ice mass in Zone 3} \\
\hline & $\begin{array}{l}\text { Frequency } \\
\text { (Hz) }\end{array}$ & $\%$ change & $\begin{array}{c}\text { Frequency } \\
\text { (Hz) }\end{array}$ & $\%$ change & $\begin{array}{l}\text { Frequency } \\
\text { (Hz) }\end{array}$ & $\%$ change \\
\hline $1^{\text {st }}$ Flapwise & 0.7196 & 0.00 & 0.7169 & -0.37 & 0.6979 & -3.01 \\
\hline $1^{\text {st }}$ Edgewise & 1.1300 & -0.03 & 1.1233 & -0.62 & 1.1069 & -2.07 \\
\hline $2^{\text {nd }}$ Flapwise & 2.0146 & -0.11 & 2.0045 & -0.61 & 1.9775 & -1.95 \\
\hline $2^{\text {nd }}$ Edgewise & 4.0225 & -0.19 & 4.0173 & -0.32 & 3.9529 & -1.92 \\
\hline $3^{\text {rd }}$ Flapwise & 4.6020 & -0.19 & 4.5917 & -0.42 & 4.5234 & -1.90 \\
\hline $4^{\text {th }}$ Flapwise & 5.5488 & -0.06 & 5.5022 & -0.90 & 5.4614 & -1.63 \\
\hline $3^{\text {rd }}$ Edgewise & 8.1183 & -0.16 & 8.0969 & -0.42 & 7.9794 & -1.87 \\
\hline
\end{tabular}


Wind Energ. Sci. Discuss., doi:10.5194/wes-2016-30, 2016

Manuscript under review for journal Wind Energ. Sci.

Published: 7 September 2016

(c) Author(s) 2016. CC-BY 3.0 License.

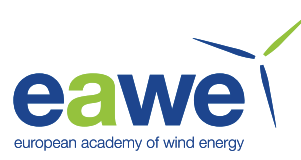

\section{ARTIFICIAL NEURAL NETWORKS (ANN)}

Artificial Neural Networks are inspired from the biological neural networks, where artificial nodes known as neurons are connected together to form a network. ANN can be used to estimate or approximate functions that depend on multiple variables. The network receives inputs from the neurons in the input layer, and the output of the network is given by the neurons in the output layer. There may be one or more intermediate hidden layer. The neurons in the network are connected with each other and associated with some weights. These weights are determined in the training process where the relation between input and output variables is determined (Ata, 2015). The backpropagation algorithm is the most widely used algorithms to determine the weights of neurons organized in layers. In this algorithm, the network signal travels in the forward direction and the errors are propagated backward. The algorithm is provided with a set of inputs and outputs; the

10 error (difference between actual and expected results) is calculated for each input and corresponding output. The network training begins with random weights, and then adjusted till the error is minimal. Once the network is trained, it can be used to identify output variables for any given input variables. The prediction can be improved by increasing the number of neurons and training the network with large data set that covers a wider range of input variable combinations. The advantage of ANN is that it only needs inputs and outputs of the process to approximate underlying complex nonlinear functions. In

15 this study, a nonlinear function which considers blade natural frequencies as input and the ice mass accumulated in the three zones as output is approximated using ANN.

In this study, different ice mass values between zero and a maximum value of ice mass (626 kg, defined by GL limit shown in Figure 7(b)) are considered in each zone. This range is divided into $n$ equally spaced values, so $(n+1)$ values are possible for ice mass in each zone. Then, $(n+1)^{3}$ combinations of ice masses in the three zones are possible; these ice masses are distributed with corresponding constant linear mass densities (mass per unit length). Each guideline defines ice mass distribution differently in the three zones in Figure 6, instead of considering any of these mass distributions, ice masses are distributed with different linear mass densities in the three zones and used to simulate natural frequencies of the blade using the FEM model of the blade. Thus a data set of size $(n+1)^{3}$ is created to train the ANN with blade natural frequencies as inputs and corresponding ice mass values in the three zones as outputs. The dataset is randomly divided into three groups:

$2570 \%$ for training, $15 \%$ for validation and $15 \%$ for testing. Levenberg-Marquardt backpropagation algorithm (MATLAB Neural network toolbox, n.d.) is used in this study to identify ice masses in three different zones ( 3 output variables) defined along the blade length with first 3 flapwise and 2 edgewise natural frequencies as the inputs (total 5 input variables). The neural network model used in this study is shown in Figure 8 with input and output layers. The backpropagation algorithm determines the weights of the neurons so that the error between outputs of the neural network model and the actual output values of the training data set is minimized. The algorithm achieves an acceptable mean square error of 0.0014 at the end of 1000 epochs (In the neural network terminology: one epoch means one forward pass and one backward pass of all the training data) in Figure 9. The neural network model is now well fitted to the training data and it is tested for some ice mass distributions in the next section. 
Wind Energ. Sci. Discuss., doi:10.5194/wes-2016-30, 2016

Manuscript under review for journal Wind Energ. Sci.

Published: 7 September 2016

(c) Author(s) 2016. CC-BY 3.0 License.
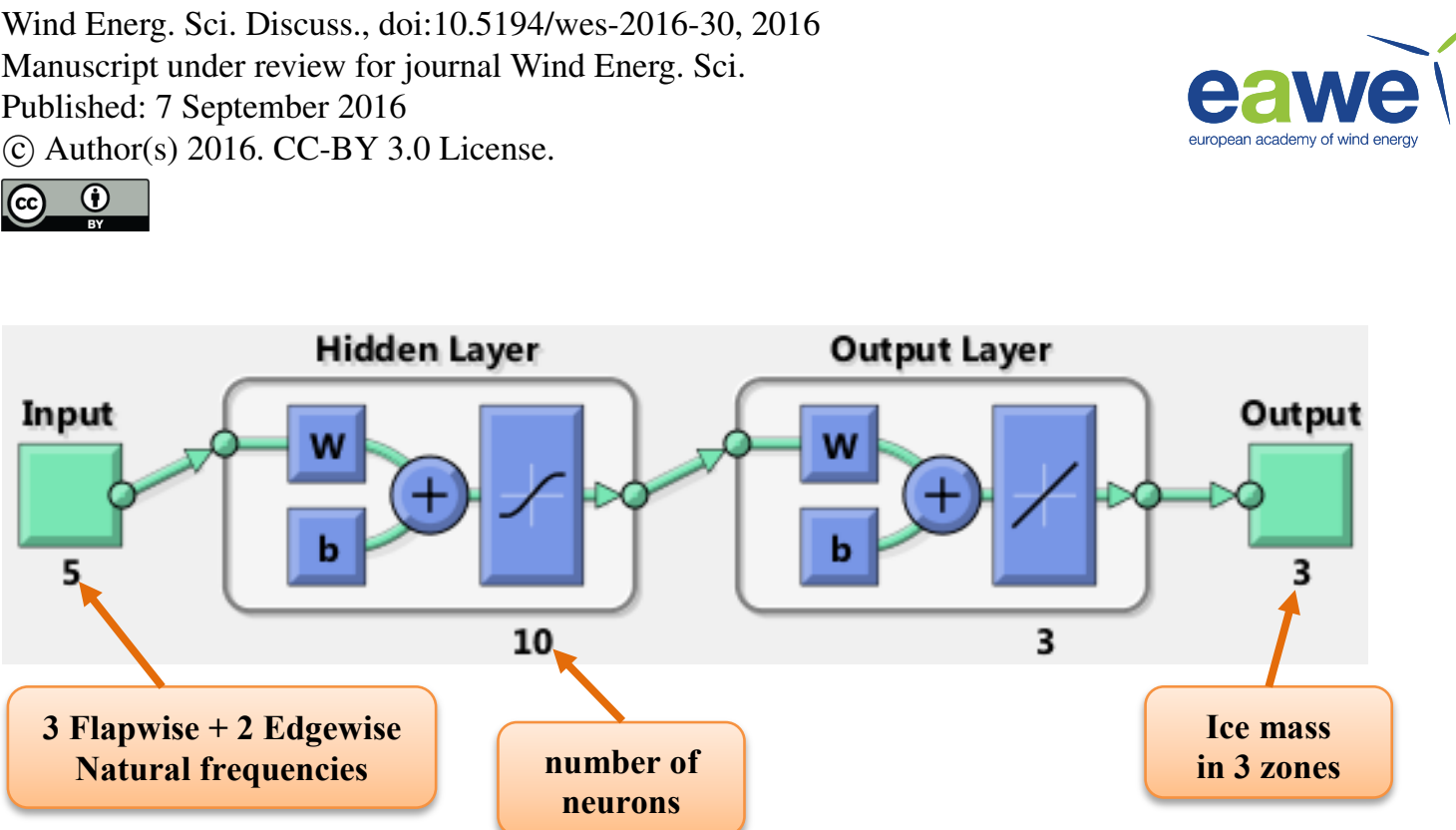

Figure 8. Artificial Neural Network diagram with inputs and outputs

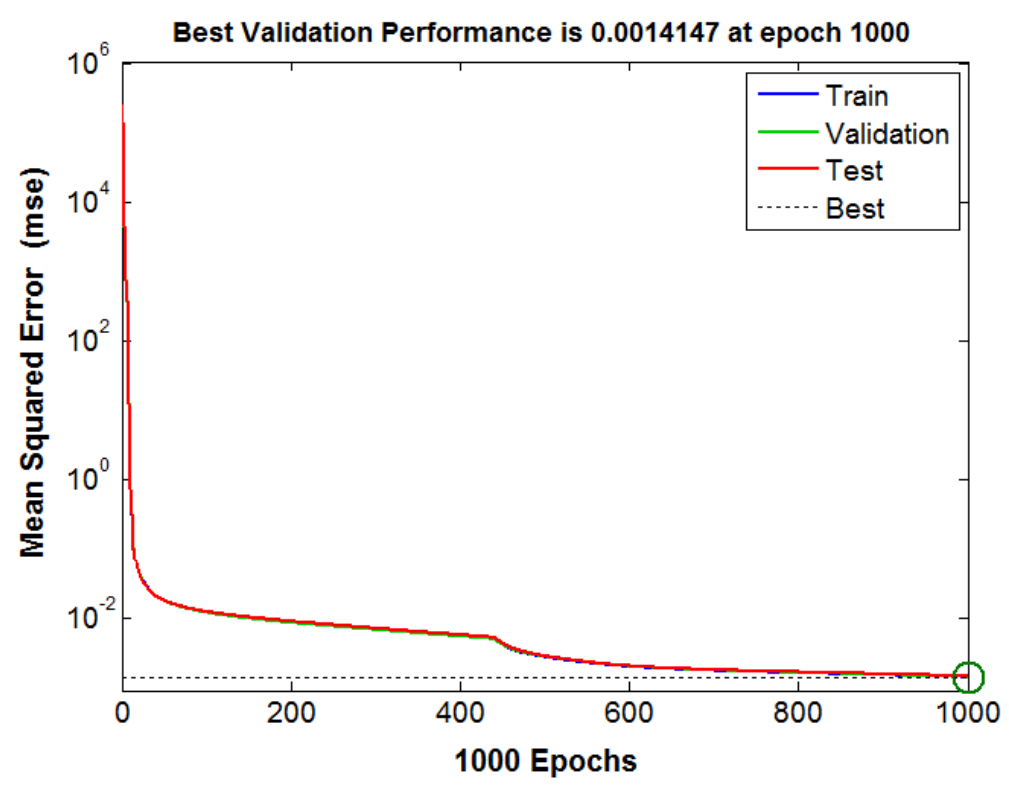

Figure 9. Mean squared error convergence of the training data

\section{RESULTS \& DISCUSSIONS}

In this section, ten ice mass validation cases as shown in Figure 10 are considered along the blade and simulated their natural frequencies. These frequencies are used as inputs to different neural network models to identify: the minimum detectable ice mass; the influence of neural network variables like number of blade natural frequencies used in the input, the number of samples used in the neural network training and number of neurons used in the hidden layers on the prediction accuracy. The

15 ANN model described in the Section IV used 5 natural frequencies of the blade as input, a new network model with 7 natural frequencies (4 flapwise +3 edgewise vibration modes) as input is considered in this section. The range between minimum and maximum ice mass values in each zone is divided into 20 (i.e., $\mathrm{n}=20$ ) divisions in the last section which generated a data 
Wind Energ. Sci. Discuss., doi:10.5194/wes-2016-30, 2016

Manuscript under review for journal Wind Energ. Sci.

Published: 7 September 2016

(c) Author(s) 2016. CC-BY 3.0 License.

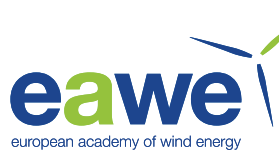

set of size 9261 samples, in this section it is divided into 25 divisions which generates a data set of size 17576 samples. To check the influence of number of neurons on the prediction accuracy, they are increased to 20 in this section from 10 in the last section. Different ANN models are created by changing one parameter in each model as defined in Table 3 and trained with data sets of blade natural frequencies and the ice masses considered on the blade. These network models are then given blade natural frequencies corresponding to the ice mass validation cases as inputs. The ice mass values predicted by neural network models created with different input parameters are compared in Table 4 with the actual ice mass values used in the validation cases.
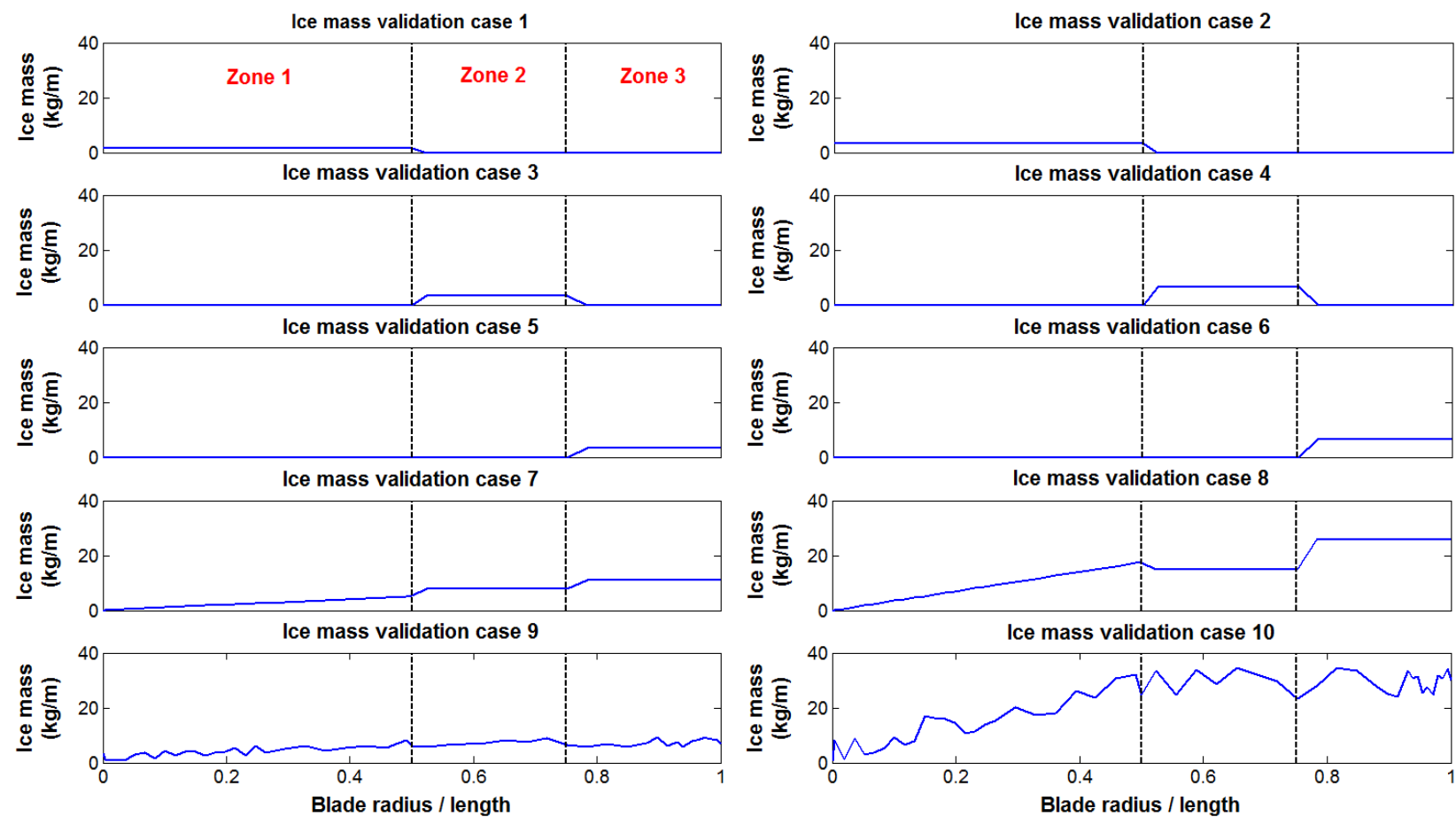

Figure 10. Ice mass distributions along the blade considered in the validation cases

Table 3: Input parameters used in different network models

\begin{tabular}{c|ccccc}
\hline $\begin{array}{c}\text { Neural network } \\
\text { inputs }\end{array}$ & $\mathbf{5}$ & $\mathbf{2}$ & $\mathbf{3}$ & $\mathbf{4}$ & $\mathbf{5}$ \\
\hline No. of neurons & 10 & 20 & 10 & 10 & 20 \\
\hline Training data size & 9261 & 9261 & 17576 & 9261 & 17576 \\
\hline $\begin{array}{c}\text { No. of input } \\
\text { frequencies }\end{array}$ & $5^{\#}$ & $5^{\#}$ & $5^{\#}$ & $7^{*}$ & $7^{*}$ \\
\hline
\end{tabular}

\# 3 flapwise +2 edgewise natural frequencies, " 4 flapwise +3 edgewise natural frequencies 
Wind Energ. Sci. Discuss., doi:10.5194/wes-2016-30, 2016

Manuscript under review for journal Wind Energ. Sci.

Published: 7 September 2016

(c) Author(s) 2016. CC-BY 3.0 License.

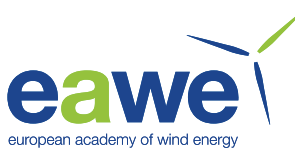

In ice mass validation cases 1-6, small ice masses (approximately $50 \mathrm{~kg}, 100 \mathrm{~kg}$, i.e., $0.28 \%$ and $0.56 \%$ of blade mass) with constant linear mass densities are considered along the blade as shown in Figure 10. The network models created with input parameters defined in Table 3 are accurately predicting these small ice masses as all network models are trained with similar ice mass distributions (constant linear mass densities) along the blade. Whereas in the cases 7 and 8 , ice mass is

5 not well predicted in Zone-1. In these cases, the ice mass distribution in Zone-1 is linearly increasing from the blade root to middle of the blade length similar to the GL ice mass distribution, but the training data (input to neural network models) are generated considering ice mass with constant linear mass density in Zone-1. This introduced some error in the ice masses predicted in Zone-1. Ice mass is distributed randomly in cases 9 and 10 which is close to the reality, all network models are only able to predict ice masses in the three zones approximately. ANN approximates non-linear function between ice masses distributed with constant linear mass densities and blade natural frequencies used in the training data, ice masses can be accurately predicted using the trained model only if the input natural frequencies correspond to ice masses distributed with constant linear mass densities. But, the actual ice mass distribution in cases $7-10$ is quite different from the ice mass distributions used in the training data, so ice masses are predicted with an error which are shown in Figure 11. The error decreases with increase in ice mass i.e., from case 7 to case 8 and case 9 to case 10 (see Figure 11).

Table 4: Ice masses predicted using different network models in the ice mass validation cases

\begin{tabular}{|c|c|c|c|c|c|c|c|}
\hline \multirow{3}{*}{$\begin{array}{c}\text { Ice mass } \\
\text { validation } \\
\text { case no. }\end{array}$} & \multirow{3}{*}{\multicolumn{2}{|c|}{$\begin{array}{l}\text { Actual ice mass } \\
\text { values }(\mathrm{kg})\end{array}$}} & \multicolumn{5}{|c|}{ Predicted ice mass values (kg) } \\
\hline & & & \multicolumn{5}{|c|}{ Network model no. } \\
\hline & & & 1 & 2 & 3 & 4 & 5 \\
\hline \multirow{3}{*}{1} & Zone 1 & 50 & 50 & 50 & 50 & 50 & 50 \\
\hline & Zone 2 & 1 & 0 & 0 & 0 & 0 & 0 \\
\hline & Zone 3 & 0 & 0 & 0 & 0 & 0 & 0 \\
\hline \multirow{3}{*}{2} & Zone 1 & 100 & 100 & 100 & 100 & 100 & 100 \\
\hline & Zone 2 & 2 & 0 & 0 & 0 & 0 & 0 \\
\hline & Zone 3 & 0 & 0 & 0 & 0 & 0 & 0 \\
\hline \multirow{3}{*}{3} & Zone 1 & 0 & 0 & 0 & 0 & 0 & 0 \\
\hline & Zone 2 & 48 & 48 & 48 & 48 & 47 & 47 \\
\hline & Zone 3 & 3 & 0 & 0 & 0 & 0 & 0 \\
\hline \multirow{3}{*}{4} & Zone 1 & 0 & 0 & 0 & 0 & 0 & 0 \\
\hline & Zone 2 & 96 & 96 & 96 & 97 & 95 & 94 \\
\hline & Zone 3 & 7 & 0 & 0 & 1 & 0 & 0 \\
\hline \multirow{2}{*}{5} & Zone 1 & 0 & 0 & 0 & 0 & 0 & 0 \\
\hline & Zone 2 & 0 & 6 & 6 & 3 & 0 & 13 \\
\hline
\end{tabular}


Wind Energ. Sci. Discuss., doi:10.5194/wes-2016-30, 2016

Manuscript under review for journal Wind Energ. Sci.

Published: 7 September 2016

(c) Author(s) 2016. CC-BY 3.0 License.

\begin{tabular}{c|c|c|ccccc} 
& Zone 3 & 47 & 49 & 48 & 47 & 50 & 46 \\
\hline \multirow{3}{*}{6} & Zone 1 & 0 & 0 & 0 & 0 & 0 & 0 \\
& Zone 2 & 0 & 9 & 11 & 5 & 0 & 23 \\
& Zone 3 & 93 & 99 & 96 & 95 & 100 & 92 \\
\hline \multirow{3}{*}{7} & Zone 1 & 81 & 23 & 6 & 24 & 70 & 12 \\
& Zone 2 & 118 & 131 & 138 & 125 & 104 & 150 \\
& Zone 3 & 165 & 167 & 163 & 161 & 169 & 157 \\
\hline \multirow{3}{*}{$\mathbf{8}$} & Zone 1 & 269 & 209 & 170 & 195 & 302 & 180 \\
& Zone 2 & 235 & 243 & 277 & 235 & 192 & 279 \\
\multirow{3}{*}{9} & Zone 3 & 382 & 391 & 382 & 377 & 395 & 372 \\
& Zone 1 & 133 & 103 & 93 & 101 & 140 & 96 \\
& Zone 2 & 112 & 146 & 154 & 145 & 130 & 164 \\
& Zone 3 & 107 & 111 & 108 & 105 & 110 & 102 \\
\hline \multirow{3}{*}{$\mathbf{1 0}$} & Zone 1 & 492 & 517 & 485 & 505 & 648 & 492 \\
& Zone 2 & 466 & 481 & 519 & 472 & 390 & 503 \\
& Zone 3 & 450 & 446 & 436 & 431 & 457 & 424 \\
\hline
\end{tabular}

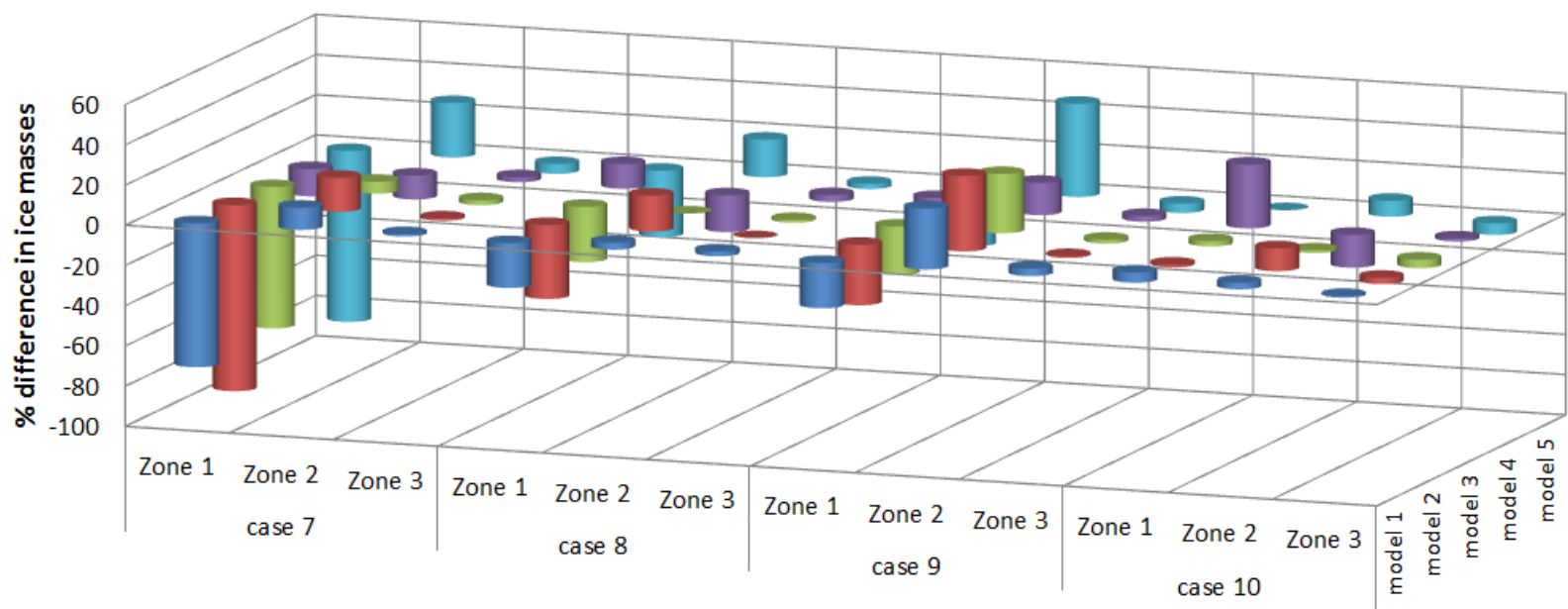

\begin{tabular}{|c|c|c|c|c|c|c|c|c|c|c|c|c|}
\hline & \multicolumn{3}{|c|}{ case 7} & \multicolumn{3}{|c|}{ case 8} & \multicolumn{3}{|c|}{ case 9} & \multicolumn{3}{|c|}{ case 10} \\
\hline & Zone 1 & Zone 2 & Zone 3 & Zone 1 & Zone 2 & Zone 3 & Zone 1 & Zone 2 & Zone 3 & Zone 1 & Zone 2 & Zone 3 \\
\hline model 1 & -72 & 11 & 1 & -22 & 3 & 2 & -23 & 30 & 4 & 5 & 3 & -1 \\
\hline model 2 & -93 & 17 & -1 & -37 & 18 & 0 & -30 & 38 & 1 & -1 & 11 & -3 \\
\hline model 3 & -70 & 6 & -2 & -28 & 0 & -1 & -24 & 29 & -2 & 3 & 1 & -4 \\
\hline model 4 & -14 & -12 & 2 & 12 & -18 & 3 & 5 & 16 & 3 & 32 & -16 & 2 \\
\hline model 5 & -85 & 27 & -5 & -33 & 19 & -3 & -28 & 46 & -5 & 0 & 8 & -6 \\
\hline
\end{tabular}

Figure 11. Error between ice masses predicted and actual ice mass values used in the validation cases 7 to 10 
Wind Energ. Sci. Discuss., doi:10.5194/wes-2016-30, 2016

Manuscript under review for journal Wind Energ. Sci.

Published: 7 September 2016

(c) Author(s) 2016. CC-BY 3.0 License.

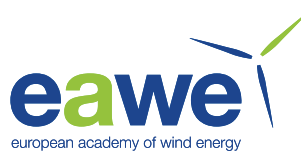

Neural network models created in this section differ either in the number of neurons or the weights associated with them because of different input parameters, so ice masses predicted in each case are slightly differing from one another. Network models created with each set of input parameters defined in Table 3 are approximately predicting ice masses in the three zones. It is not possible to estimate the ice mass exactly for whatever parameters chosen to create network models if the ice mass distribution in validation cases (like cases 7-10) is different from the ice mass distribution used to generate the training data. So, any set of input parameters in Table 3 can be used to create the network model. In general, network model parameters considered in this study are not significantly changing the predicted ice mass values. Neural network model 4 predicts ice masses relatively better than the other models. The neural network models trained with data generated using constant linear mass densities along the blade are predicting random ice mass distributions reasonably. The nature of ice

10 mass distribution differs from site to site based on the cloud heights, hub height and rotor diameter, so site specific ice mass distributions can be captured using automatic cameras installed on nacelle or spinner (Cattin, 2012). Training data with similar ice mass distributions can be generated to improve the accuracy of ice mass detection. This paper demonstrates the idea to detect average ice mass accumulated in three different zones defined along the blade using the information about blade natural frequencies. These frequencies can be measured using ice detection systems currently available in the market

15 like BLADEControl and fos4blade IceDetection systems. The authors are planning to try this idea on, a scaled down wind turbine by adding different ice masses along the blade.

\section{CONCLUSIONS}

Ice accumulation on the blade reduces its natural frequencies and these frequencies reduce differently with the amount of ice mass and their location. This behavior is used in the current work to identify average ice mass accumulated in the three zones defined along the blade using an Artificial Neural Networks model. The network model is trained with a data set of iced blade natural frequencies (first few flapwise and edgewise modal frequencies obtained from simulations) as input and ice masses used in the three zones as output. The trained network model is then used to find the ice masses in ten validation cases. The ANN models predict even ice mass of $50 \mathrm{~kg}$ which is equal to $0.28 \%$ of the mass of the NREL $5 \mathrm{MW}$ wind turbine blade in all the three zones when the ice mass in validation cases is distributed in the same way as used in the training data set, otherwise ice masses are predicted with an error. Overall, the proposed technique predicts the ice mass distribution along the blade approximately which is otherwise not possible before. The technique is only demonstrated using simulation data by considering different ice masses along the blade and this technique needs to be validated with experimental data. The results shown in this study encourage continuing this work as it only needs measurements of the ice detection systems currently available in the market. Another advantage of this technique is that it only needs a data set of simulated blade natural frequencies with different ice masses along the blade which can be provided by the turbine manufacturer. 
Wind Energ. Sci. Discuss., doi:10.5194/wes-2016-30, 2016

Manuscript under review for journal Wind Energ. Sci.

Published: 7 September 2016

(c) Author(s) 2016. CC-BY 3.0 License.

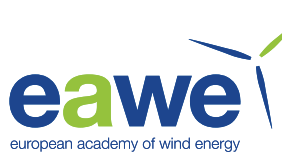

Acknowledgements: This research work is carried out as a part of the project on "Wind power in cold climates" funded by the Swedish Energy Agency which supports research and development investments in wind power.

\section{APPENDIX}

Coupled partial differential equations governing wind turbine blade axial, edgewise, flapwise and torsional 5 vibrations are given below.

$$
\begin{aligned}
& \rho A\left(\ddot{u}-2 \Omega \dot{v}+2 \Omega a_{2} \dot{\varphi}-\Omega^{2} u\right)-\left(E A u^{\prime}\right)^{\prime}=\rho A \Omega^{2}(x+h)+\rho A g \cos (\Omega t)+f_{u} \\
& \rho A\left\{\ddot{v}-a_{2} \ddot{\varphi}+2 \Omega \dot{u}-\Omega^{2}\left(v-a_{2} \varphi\right)\right\}+\left(E I_{z} v^{\prime \prime}+E I_{y z} w^{\prime \prime}\right)^{\prime \prime}-\left(F_{a x} v^{\prime}\right)^{\prime}=\rho A \Omega^{2} a_{1}-\rho A g \sin (\Omega t)+f_{v} \\
& \rho A\left(\ddot{w}+a_{1} \ddot{\varphi}\right)+\left(E I_{y} w^{\prime \prime}+E I_{y z} v^{\prime \prime}\right)^{\prime \prime}-\left(F_{a x} w^{\prime}\right)^{\prime}=f_{w} \\
& \rho A\left\{\left(a_{1}^{2}+a_{2}^{2}\right) \ddot{\varphi}-a_{2} \ddot{v}+a_{1} \ddot{w}-2 \Omega a_{2} \dot{u}+\Omega^{2} a_{2}\left(v-a_{2} \varphi\right)\right\}+J_{P}\left(\ddot{\varphi}-\Omega^{2} \varphi\right)-\left(G J \varphi^{\prime}\right)^{\prime} \\
& =\rho A g a_{2} \sin (\Omega t)-\rho A \Omega^{2} a_{1} a_{2}+f_{\varphi}
\end{aligned}
$$

10 where, $a_{1}=e_{\eta} \cos \theta-e_{\xi} \sin \theta ; a_{2}=e_{\eta} \sin \theta+e_{\xi} \cos \theta$.

\section{References}

Alsabagh, A. S. Y. et al.: Atmospheric Ice Loading and Its Impact on Natural Frequencies of Wind Turbines, Wind Engineering, 39 (1), pp. 83-96, 2015.

Ata, R.: Artificial neural networks applications in wind energy systems: a review, Renewable and Sustainable Energy Reviews, 49, 534-562, 2015.

Brenner, D.: 1,500 operational years of icing on wind turbines - A long term study, Winterwind 2015, Feb 3-4, Piteå, Sweden, 2015.

Brenner, D.: Determination of the actual ice mass on wind turbine blades", Winterwind 2016, Feb 9-10, Åre, Sweden, 2016.

Cattin, R. et al.: Evaluation of ice detection systems for wind turbines, Final Report, VGB Research Project No. 392, Available at: https://www.vgb.org/vgbmultimedia/392_Final+report-p-10476.pdf, 2016 (Accessed: 13 August 2016).

Cattin, R.: Icing of wind turbines: Vindforsk projects, a survey of the development and research needs, Elforsk report 12:13, Available at: http://www.elforsk.se/Global/Vindforsk/Survey\%20reports/12_13_report_icing.pdf, 2012 (Accessed: 13 August 2016).

Etemaddar, M., Hansen, M. O. L. and Moan, T.: Wind turbine aerodynamic response under atmospheric icing conditions, Wind Energ., 17: 241-265, doi: 10.1002/we.1573, 2014. 
Wind Energ. Sci. Discuss., doi:10.5194/wes-2016-30, 2016

Manuscript under review for journal Wind Energ. Sci.

Published: 7 September 2016

(c) Author(s) 2016. CC-BY 3.0 License.

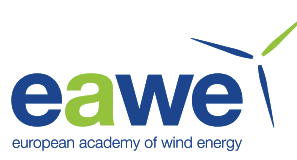

fos4X data sheet: fos4Blade IceDetection, Available at: http://www.fos4x.de/sites/default/files/field_downloads/0307_1-2-

0_4-20_01_fos4Blade_IceDetection.pdf (Accessed: 13 August 2016).

Gantasala, S. et al.: Wind turbine with iced blades: Stability analysis of coupled blade's in-plane and tower motions, $11^{\text {th }}$ EAWE PhD Seminar on Wind Energy in Europe, 23-25 September, Stuttgart, Germany, 2015.

5 Germanischer Lloyd: Guideline for the Certification of Wind Turbines, Edition 2010, Germanischer Lloyd, Hamburg, 2010.

Gunjit, B.: BModes - Software for Computing Rotating Blade Coupled Modes, Available at: https://nwtc.nrel.gov/BModes,

(Accessed: 13 August 2016).

Ilinca, A.: Analysis and Mitigation of Icing Effects on Wind Turbines, Wind Turbines, Dr. Ibrahim Al-Bahadly (Ed.), ISBN: 978-953-307-221-0, InTech, Available from: http://www.intechopen.com/books/windturbines/analysis-and-mitigationof-icing-effects-on-wind-turbines, 2011.

International Standardisation Organisation: ISO 12494:2001, Atmospheric Icing of Structures, 2001.

Jonkman, J., Butterfield, V., Musial, W. and Scott, G.: Definition of a 5-MW Reference Wind Turbine for Offshore System Development, National Renewable Energy laboratory, Technical report, NREL/TP-500-38060, 2009.

Kim, K. T. and Lee, C. W.: Coupled bending and torsional vibration analysis of flexible wind turbine blades by using assumed modes method, 15th International Congress on Sound and Vibration, 6-10 July, Daejeon, Korea, 2008.

King, T.: Improving turbine energy generation and reliability in cold climates, Winterwind 2008, December 9-10 in Norrköping, Sweden, 2008.

Lorenzo, E. D. et al.: Virtual Structural Monitoring of Wind Turbines Using Operational Modal Analysis Techniques, Key Engineering Materials, Vols. 569-570, pp. 523-530, 2013.

MATLAB Neural Network Toolbox: Levenberg-Marquardt backpropagation algorithm, Available from: http://se.mathworks.com/help/nnet/ref/trainlm.html (Accessed: 13 August 2016).

Navigant Research: BTM World Market Update 2012, Special Chapter: Cold Climate Turbines, Copenhagen, Denmark, 2012.

Peltola, E., Laakso, T., Antikainen, P. and Peuranen, S. Prevention of Icing Effects, BOREAS VI. FMI, Pyhätunturi, Finland, pp. 9, 2003.

Rindeskär, E.: Modelling of icing for wind farms in cold climate, Examensarbete vid Institutionen för Geovetenskaper, ISSN 1650-6553 Nr 201, 2010.

Rissanen, S. et al.: Modelling load and vibrations due to iced turbine operation, Wind Engineering, 40 (3), 293-303, 2016.

Skrimpas, G. A. et al.: Detection of icing on wind turbine blades by means of vibration and power curve analysis, Wind Energ., doi: 10.1002/we.1952, 2015.

Turkia, V., Huttunen, S. and Wallenius, T.: Method for estimating wind turbine production losses due to icing, VTT Technology: 114, Espoo, VTT, 38 p., ISBN 978-951-38-8041-5, 2013. 